九州大学学術情報リポジトリ

Kyushu University Institutional Repository

\title{
Up-regulation of circadian clock gene Period 2 in the prostate mesenchymal cells during flutamide-induced apoptosis
}

\section{Yoshida, Kaoru}

Department of Animal and Marine Bioresource Sciences, Faculty of Agriculture, Kyushu University

He, Pei-Jian

Department of Medicine, Emory University School of Medicine I Department of Animal and Marine Bioresource Sciences, Faculty of Agriculture, Kyushu University

Yamauchi, Nobuhiko

Department of Animal and Marine Bioresource Sciences, Faculty of Agriculture, Kyushu University

Hashimoto, Seiichi

Molecular Medicine Research Laboratories, Drug Discovery Research, Astellas Pharma Inc. | Department of Technology Development, Innovation Headquarters, Japan Science and Technology Agency

他

http://hdl. handle. net/2324/26624

出版情報: Molecular and Cellular Biochemistry. 335 (1/2)，pp.37-45，2010-02-01. Springer US バージョン :

権利関係: (C) Springer Science+Business Media, LLC. 2009 
TITLE:

Up-regulation of circadian clock gene Period 2 in the prostate mesenchymal cells during flutamide-induced apoptosis

\section{AUTHORS AND AFFILIATIONS:}

Kaoru Yoshida ${ }^{1}$, Pei-jian $\mathrm{He}^{1} \S$, Nobuhiko Yamauchi ${ }^{1}$, Seiichi Hashimoto ${ }^{2} \#$ and Masa-aki Hattori ${ }^{1} *$

${ }^{1}$ Department of Animal and Marine Bioresource Sciences, Faculty of Agriculture, Kyushu University, Fukuoka-shi, Fukuoka 812-8581; ${ }^{2}$ Molecular Medicine Research Labs, Drug Discovery Research, Astellas Pharma Inc, Miyukigaoka 21, Tsukuba-shi, Ibaraki 305-8585, Japan

*CORRESPONDENCE to: Masa-aki Hattori

Phone \& FAX: +81-92-642-2938, E-mail address: mhattori@agr.kyushu-u.ac.jp

§Present address: Department of Medicine, Emory University School of Medicine, Atlanta, Georgia 30322, USA

\# Present address: Department of Technology Development, Innovation Headuarters, Japan Science and Technology Agency, 5-3, Yobanchou, Chiyoda-ku, Tokyo 102-8666, Japan. 


\section{Abstract}

Androgen regulates the proper development and physiological function of the prostate.

Here we investigated on the modulation of androgen and androgen receptor (AR) antagonist on circadian oscillations of a clock core gene Period $2($ Per2) in rat prostate mesenchymal cells (PMCs). Circadian oscillations were analyzed with the real-time monitoring system of gene expression using transgenic rats introduced with mouse Per2 promoter fused to a destabilized luciferase (Per2-dLuc) reporter gene. Analyses of circadian oscillations, immunofluorescence and androgen response element (ARE)-luciferase reporter assay revealed that circadian clocks are operative and the $\mathrm{AR}$ protein is functional in PMCs in vitro. Androgen such as testosterone and dihydrotestosterone did not cause any changes in circadian Per2-dLuc oscillations of confluent cells. Conversely, flutamide (FL) up-regulated the amplitude of circadian Per2-dLuc oscillations in a dose-dependent manner, whereas testosterone antagonized the action of FL. The PER2 protein was markedly accumulated by FL treatment and localized in both the nucleus and cytoplasm during the first peak period of circadian Per2-dLuc oscillations. Simultaneously, FL treatment increased apoptotic cell death. Collectively, the present study demonstrates that a clock gene Per2 is up-regulated in PMCs during FL-induced apoptotic cell death. Thus, circadian oscillations of Per2 gene expression may be closely linked to the cellular states of PMCs such as apoptotic cell death. 


\section{Key words}

Period 2; Per2-dLuc oscillations; prostate mesenchymal cells; flutamide; androgen;

apoptosis 


\section{Introduction}

Physiology, pathology and metabolism in mammals are influenced by circadian rhythms, which are integrated by the master pacemaker located in the suprachiasmatic nucleus $(\mathrm{SCN})$ of the hypothalamus [1]. At the molecular level, the pacemaker is composed of transcriptional and translational feedback core loops. The CLOCK and BMAL1, associated as heterodimers, bind to canonical E-Box cis-elements, and positively drive the expression of the Period genes (Per1, Per2 and Per3) and Cryptochrome genes, whose proteins, in turn, form multimeric complexes and feed back to repress the transactivation by CLOCK/BMAL1 in the nucleus [1-3].

The master pacemaker synchronizes the peripheral circadian clocks through complex interaction of neural, humoral, and behavioral cues [4, 5]. Autonomic circadian clocks are also operative in various peripheral tissues including the heart, liver, kidney, lung, spleen, adrenal gland, skeletal muscles [6, 7], and uterus [8-11]. In contrast, thymocytes, Leydig cells, and ovarian immature granulosa cells [12-16] lack their functions. So far, the identification of resetting cues and their regulatory effects on circadian clocks are mostly based on molecular biological studies in cultured cell lines. A variety of factors have been unraveled having the potential to reset circadian clocks in peripheral cells [17-23]. Glucocorticoid, for example, can efficiently activate Per1 expression and synchronize circadian oscillations of clock genes in cultured cells, also being able to phase-shift the circadian rhythms in peripheral tissues [19]. In the rat 
Per2 gene, many regulatory cis-elements are in the upstream from its transcription start site, such as estrogen response cis-element (ERE)-half and progestin/glucocorticoid/androgen response cis-element (PRE/GRE/ARE)-half sites as well as E-Box and D-Box cis-elements. Our recent studies have indicated that both estradiol (E2) and progesterone (P4) up-regulate Per2 gene expression, and P4 especially plays a pivotal role in the circadian clocks of the uterus endometrial stromal cells $[10,11]$. Steroid hormones may be regulators for circadian oscillations of clock genes in the hormone target tissues.

Androgens play an important role in the proper development and physiological function of the prostate $[24,25]$. In the prostate mesenchymal (PMCs) and epithelial cells, the action of testosterone (T) or dihydrotestosterone (DHT) is initiated by their binding to the intracellular androgen receptor (AR). Then, the androgen-bound receptor complex binds to AREs in the promoter regions of target genes, and transcriptional regulation occurs in a ligand-dependent manner. Since both T and DHT modulate the growth of normal and malignant prostate tissues, androgen ablation and antiandrogen hormonal therapy, including flutamide (FL), are effective for the early-stage prostate cancer [26, 27]. Recent studies have reported that down-regulation of Per2 gene expression accelerates breast cancer growth by altering its circadian oscillations [28] and Per2 overexpression induces apoptosis in murine lung and breast cancer cell lines [29]. However, there is little literature concerning the steroid hormone 
regulation of circadian clocks in the prostate. From these recent studies, we can raise the intriguing possibility of androgen and $A R$ antagonist participation in the modulation of circadian oscillations of clock genes in the normal prostate cells.

Here we focus on the modulation of androgen and AR antagonist on circadian oscillations of a clock core gene Per2 in rat PMCs in vitro. The real-time monitoring system of gene expression was employed to evaluate circadian clocks using transgenic rats constructed with mouse Per2 promoter-destabilized luciferase (Per2-dLuc) reporter gene [30]. In the present study, we extend our recent studies to prove the differential roles of androgen and an AR antagonist FL in circadian clocks of PMCs. Our results proved up-regulation of clock gene Per2 in PMCs during FL-induced apoptotic cell death.

\section{Materials and methods}

\section{Chemicals}

T, FL, DHT, dexamethasone (DXM), forskolin, D-luciferin sodium salt, and Hoechst were purchased from Sigma Chemical (St. Louis, MO). DMEM/F12, collagenase (type I), DNase I, hyaluronidase, and penicillin-streptomycin (PS) were from GIBCO (Grand Island, NY), and propidium iodide (PI) was from Dojindo (Kumamoto, Japan). Fetal bovine serum (FBS) was from BioSource International (Camarillo, CA), and treated with dextran-coated charcoal. Anti-PER2 (H-90) and anti-AR polyclonal antibodies 
were from Santa Cruz Biotechnology (Santa Cruz, CA), and anti-rabbit IgG conjugated with fluorescein was from Leinco Technologies (St. Louis, MO).

\section{Animals}

All the experiments were performed under the control of the Guideline for Animal Experiment in Faculty of Medicine, Kyushu University and The Law (No. 105) and Notification (No. 6) of the Government. Mouse Per2 promoter region (chr1 (-): 93289505-93293019 on the Build 36 assembly by NCBI and the Mouse Genome Sequencing Consortium) was fused to a $d L u c$ reporter gene [30]. Per2- $d L u c$ transgenic rats were generated in accordance with the method described in the patent publication number WO/2002/081682 (Y.S. New Technology Institute, Utsunomiya, Japan). Transgenic and normal rats were maintained under 12-h light and 12-h dark (light between 0800 and 2000) with water and food ad libitum.

\section{Preparation and culture of PMCs}

PMCs were prepared from mature rats as described previously [31], with slight modifications. Briefly, small pieces of ventral prostates were washed 3 times with sterile PBS, and treated at $37^{\circ} \mathrm{C}$ for $20 \mathrm{~min}$ in a shaking water bath in PBS containing 1 $\mathrm{mg} / \mathrm{ml}$ collagenase, $1 \mu \mathrm{g} / \mathrm{ml}$ DNase I, $10 \mu \mathrm{M}$ EGTA, and $0.1 \%$ bovine serum albumin (BSA). Then, small pieces of ventral prostates treated were incubated at $37^{\circ} \mathrm{C}$ for 30 
min in a shaking water bath in PBS containing $1 \mathrm{mg} / \mathrm{ml}$ collagenase, $1 \mu \mathrm{g} / \mathrm{ml}$ DNase I, $1 \mathrm{mg} / \mathrm{ml}$ hyaluronidase, $10 \mu \mathrm{M}$ EGTA, and $0.1 \%$ BSA. The dispersed clumps of cells and single cells were passed through $80-\mu \mathrm{m}$ stainless mesh and the fragments were dispensed. The harvested cells were washed 3 times with phenol red free DMEM/F12 containing $10 \%$ charcoal-treated FBS and $1 \%$ PS and seeded onto 35-mm collagen-coated dishes (IWAKI, Chiba, Japan) at the density of $2 \times 10^{5}$ cells/dish/2 $\mathrm{ml}$. After incubation for 3 days at $37^{\circ} \mathrm{C}$, PMCs attached to the dish and floating epithelial cells were removed. Cultured PMCs were positively immunostained for vimentin (a marker protein of mesenchymal cells), with approximately 95\%, but negatively for cytokeratin (a marker of epithelial cells). After a 6-day culture, confluent cells were subjected to real-time monitoring of circadian oscillations.

\section{ARE-luciferase constructs in PMCs}

The ARE was constructed as follows: sense oligonucleotide, 5'-CGCG (AGC ACA TCG TGC TCA)6 6 -3'; antisense oligonucleotide, 5'-GATC (TGA GCA CGA TGT GCT $)_{6}-3$ '. The oligonucleotides were annealed, and inserted into the MluI and BglII sites of the pGL3-promoter luciferase reporter vector digested with the corresponding restriction enzymes. The constructed plasmid was transformed into JM 109 cells, replicated and extracted with Endo-free Plasmid Preparation Kit (Qiagen). The plasmid was transfected into subconfluent PMCs with LipofectAMINE-2000 reagent [32]. 
Upon the onset of bioluminescent measurement (time $0 \mathrm{~h}$ ), PMCs were given in replaced fresh medium supplemented with 5\% charcoal-treated FBS, 1\% PS, 15 mM HEPES, $0.1 \mathrm{mM}$ luciferin, and $\mathrm{T}(1,10 \mu \mathrm{M})$ or vehicle. Luciferase activity was chronologically monitored at $37^{\circ} \mathrm{C}$ with Kronos AB-2500 (ATTO, Tokyo, Japan).

\section{Real-time monitoring of circadian oscillations}

Upon the onset of bioluminescent measurement (time $0 \mathrm{~h}$ ), cultured PMCs were given in replaced fresh medium supplemented with 5\% charcoal-treated FBS, 1\% PS, 15 mM HEPES, $0.1 \mathrm{mM}$ luciferin, and various concentrations of T, DHT, or FL dissolved in absolute ethanol, with final ethanol concentration of below $0.01 \%$. Cultured PMCs were also treated with $0.1 \mu \mathrm{M}$ DXM or $1 \mu \mathrm{M}$ forskolin as previously reported [15]. Monitoring of bioluminescence was performed for 4 days at $37^{\circ} \mathrm{C}$ using Kronos AB-2500 interfaced to computer for continuous data acquisition as previously described $[10,15,16]$.

\section{Immunofluorescence analysis}

The ventral prostate sections at $8-\mu \mathrm{m}$ thickness were fixed for $5 \mathrm{~min}$ in acetone at $-20^{\circ} \mathrm{C}$. Nonspecific binding was blocked using $2 \%$ goat serum in PBS (blocking buffer) for $30 \mathrm{~min}$. Sections were incubated for $12-18 \mathrm{~h}$ at $4^{\circ} \mathrm{C}$ with anti-PER 2 and anti-AR antibodies diluted in blocking buffer. After washing with PBS, they were 
incubated with the second antibody for $1 \mathrm{~h}$ at room temperature (RT). Sections were subsequently washed in PBS and mounted with Mount-Quick Aqueous (Daido Sangyo, Japan). Cultured PMCs were washed 3 times with PBS, fixed with $4 \%$ paraformaldehyde at RT for $20 \mathrm{~min}$, and treated for $30 \mathrm{~min}$ with $0.1 \%$ Triton X-100-PBS, and incubated in blocking buffer at RT for 30 min. PMCs were incubated at $4^{\circ} \mathrm{C}$ at $24 \mathrm{~h}$ with anti-PER2 antibody diluted in PBS containing $2 \%$ goat serum. After washing, cells were treated for $1 \mathrm{~h}$ at RT with PBS containing anti-rabbit $\operatorname{IgG}$ conjugated with fluorescein and $0.1 \mu \mathrm{g} / \mathrm{ml}$ Hoechst. PMCs were washed 3 times with PBS, and immunostaining was detected under a fluorescence microscope (Nikon, Japan).

Cell death

Cultured PMCs were washed twice with PBS, and incubated at $37^{\circ} \mathrm{C}$ for 20 min with PBS containing $5 \mu \mathrm{g} / \mathrm{ml}$ PI and $10 \mu \mathrm{g} / \mathrm{ml}$ Hoechst. After washing twice with PBS, Hoechst-positive (total cells) and PI-positive cells (apoptotic cells) were counted under a fluorescence microscope.

\section{Statistical analyses}

The quantification of immunofluorescence staining intensity was performed as previously reported [33]. A box was drawn through each compartment in a random 
orientation, and the pixel value of each box was measured by NIH Scion Image. A mean value was obtained from the determination of more than twenty boxes for each sample. All the experiments were independently repeated at least 3 times, and data were expressed as means \pm SE. The differences between them were evaluated using Student's t test. A $P$ value $<0.05$ was considered to be statistically significant.

\section{Results}

Expression of PER2 and AR proteins in PMCs

Immunofluorescent analysis using the prostates of mature rats was performed to evaluate the expression and subcellular localization of the PER2 and AR proteins. Weak immunostaining of the PER2 protein was observed in the mesenchyme, and relatively strong staining in the epithelium (Fig. 1b). The AR protein was expressed in both the mesenchyme and epithelium, especially distributed in the nuclei of both compartments (Fig. 1c). In the merged image, both the PER2 and AR proteins were detected in the mesenchyme (Fig. 1d). No staining was observed in the negative control (data not shown). The response to androgen was assessed using ARE-Luc constructs in PMCs. As the results are shown in Fig. 2, following a minor activity prior to $24 \mathrm{~h}$, there was a major peak in bioluminescence activity after $24-48 \mathrm{~h}$ of stimulation with $\mathrm{T}(1,10 \mu \mathrm{M})$, showing a dose-dependent manner. Immunostaining of the AR protein was also detected in cultured PMCs. Consequently, the AR protein is functional 
in PMCs in vitro.

\section{Circadian Per2-dLuc oscillations in PMCs}

PMCs prepared from transgenic rats were stimulated with or without DXM or forskolin, and subjected to monitoring of Per2-dLuc oscillation. As the results are shown in Fig. 3, the amplitude of oscillations was increased after exposure to either DXM or forskolin, as compared to that given by vehicle only. PMCs generated oscillations with approximately $24 \mathrm{~h}$ per cycle, although the amplitude was gradually decreasing. Thus, circadian clocks are operative in PMCs in vitro.

Effects of androgens and FL on circadian Per2-dLuc oscillations in PMCs

The effects of T, DHT, and FL on Per2-dLuc oscillations were analyzed. PMCs were stimulated with or without reagents (each $1 \mu \mathrm{M}$ ), and subjected to monitoring of Per2-dLuc oscillation. Circadian oscillations were not significantly altered after treatment with T or DHT (Fig. 4A). In contrast, FL up-regulated the amplitude of oscillations. The first (P1) and second (P2) peaks of Per2-dLuc oscillations in FL-treated cells were significantly higher than those given by treatment with T or DHT $(\mathrm{P}<0.05)$ (Fig. 4B). However, there was no significant difference in the first $(\mathrm{T} 1)$ and second (T2) troughs among all the treatments. The action of FL $(0.1-10 \mu \mathrm{M})$ was assessed for its dose-dependency. As the results are shown in Fig. 5A, FL increased the 
amplitude of oscillations, although no activity was generated at $0.1 \mu \mathrm{M}$. When the first peaks of circadian oscillations were calculated, the action of FL occurred in a dose-dependent manner (Fig. 5B).

Competitive inhibitory effect of $T$ on FL-induced circadian Per2-dLuc oscillations in PMCs

The effect of $\mathrm{T}$ on FL-induced Per2-dLuc oscillations was analyzed. PMCs were pretreated for $5 \mathrm{~h}$ with increasing concentrations of $\mathrm{T}(0.1-10 \mu \mathrm{M})$, and given in replaced fresh medium supplemented with $1 \mu \mathrm{M}$ FL, and then subjected to monitoring of oscillation. As the results are shown in Fig. 6, the pretreatment with $10 \mu \mathrm{M}$ T caused a significant decrease in the first peak of circadian oscillations stimulated by FL, showing the competitive inhibitory effect of $\mathrm{T}$ on the action of FL.

Immunofluorescent analysis of PER2 in PMCs in vitro

To further investigate the effect of FL on circadian rhythms of the PER2 protein, immunofluorescent studies were performed to analyze for its expression and localization in PMCs. In control PMCs, PER2 immunostaining was slightly higher in the first peak (34 h) than in the first trough (48 h), with several strongly stained cells (Fig. 7b, arrowheads). In the FL-treated PMCs, PER2 immunostaining was much stronger in the first peak than in the first trough. In the first peak, many cells were 
strongly stained, and round and small in size, that apoptotic cell death was induced (Fig. 7i, arrowheads). In the first peak of both cell groups, the PER2 staining signal was detected in both the nucleus and cytoplasm (Fig. 7c, g, j and n), whereas the signal was not in the cytoplasm in the first trough (Fig. 7f, m). No staining was observed in the negative control (data not shown). From the immunofluorescence observation, changes of PER2 staining intensity in PMCs were calculated by NIH Scion Image (Table 1). The intensity at P1 was 2.5 -fold of that given by the control. Also, the intensity at T1 was significantly higher that that given by the control.

Analysis of apoptosis in PMCs

To confirm apoptotic cell death, PMCs were cultured for $34 \mathrm{~h}$ (P1) and $48 \mathrm{~h}$ (T1) with $1 \mu \mathrm{M}$ FL and subjected to PI staining. As the results are shown in Fig. 8, treatment with FL caused a marked increase in cell death, with 2.5 -fold over the control in both $\mathrm{P} 1$ and $\mathrm{T} 1$.

\section{Discussion}

Several studies have demonstrated that circadian core clock genes Per1 and Per2 are rhythmically expressed in the steroid target tissues [8-11]. The purpose of this study is to analyze the regulation of circadian clocks in PMCs by androgen and AR antagonist. 
Immunofluorescent analysis and ARE-luciferase reporter assay revealed that both the PER2 and functional AR proteins were expressed in the mesenchyme, although the PER2 protein was highly expressed in the epithelial cell layer. In addition, PMCs generated strong circadian oscillations after exposure to DXM or forskolin in vitro, indicating that circadian clocks are operative.

It was next investigated if circadian clocks are influenced by androgen such as $\mathrm{T}$ and DHT in PMCs in vitro. Unexpectedly, both T and DHT did not cause any changes in circadian oscillations. T and DHT could bind to their receptor, which, in turn, interacts with its target cis-element in the promoters of target genes, thereby regulating gene transcription [34]. Other steroid hormones can differentially modulate circadian clocks in peripheral tissues. E2 does not induce circadian oscillations in the uterus stromal cells, whereas $\mathrm{P} 4$ promotes the rhythmic pattern $[10,11]$. Chronic treatment with E2 also disrupts circadian oscillations of Per1 and Per2 expression in the liver, kidney and uterus [8]. On the other hand, FL is generally used as an AR antagonist for therapy of prostate cancer [35]. Interestingly, FL dose-dependently up-regulated the amplitude of circadian oscillations in PMCs in vitro. Since the E-Box cis-elements in the Per2 promoter are essential for the binding of CLOCK/BMAL1 and generation of circadian oscillations [36, 37], FL may promote the transcription of the Per2 gene through direct or indirect transactivation of CLOCK/BMAL1. Immunofluorescent studies were performed to analyze for PER2 expression and localization in PMCs. 
During the first peak in FL-treated cells, the PER2 staining signal was detected in both the nucleus and cytoplasm, and thereafter the signal was drastically decreased in the cytoplasm during the first trough. These findings may indicate that the negative feed back loop by multimeric complexes of Period and Cryptochrome proteins is still functional in survived PMCs after FL treatment. Anyway, our present results indicate that FL is an inducer for overexpression of the Per2. Conversely, T could antagonize the action of FL. There are several reports that FL behaves as a partial agonist. FL modulates AR activity and DJ-1 in the human prostate epithelial cells [38], and also activates AR phosphorylation for expression of prostate-specific antigen in the normal prostate cell lines [39]. The agonistic action of FL may be related to SMRT (silencing mediator of retinoid and thyroid hormone receptor) and N-CoR corepressors (nuclear receptor corepressor) involved in transcriptional regulation by both agonist- and antagonist-bound AR [39]. However, if our present data resulted from the agonistic action of FL in PMCs, both T and DHT should be expected to up-regulate circadian Per2 gene oscillations. Recent studies also reported the AR-independent action of FL $[40,41]$. FL activates the expression of protein kinase C isoenzymes in CSS-LNCaP cells and can elicit responses in prostate cancer cells that do not express AR [40]. In the rat prostate, apoptosis is suppressed by binding of decoy receptor DcR2 to TNF- $\alpha$-related apoptosis-inducing ligand and is induced through the decoy receptor inhibited by FL [41]. Taken together with our present data, up-regulation of circadian 
oscillations by FL may result from both AR-dependent and -independent pathways.

Analyses of circadian oscillations using the Per2-dLuc reporter gene and immunocytochemical studies demonstrated that FL also up-regulates the PER2 protein in PMCs. Strongly immunostained cells in the first peak of circadian oscillations appeared to apoptotic cell death. These apoptotic cells were observed as small particles during the first trough. Consequently, FL-induced apoptosis may be closely related to overexpression of the PER2 protein. Several studies reported that the Per2 gene not only modulates circadian oscillations, but also regulates cellular function. The Per2 gene is reported to be tumor suppressor gene [42] and circadian disruption may increase the risk of breast cancer [43, 44]. Overexpression of the PER2 protein induces apoptosis in the mouse Lewis lung carcinoma cell line and mammary carcinoma cell line [29, 45]. Conversely, down-regulation of Per2 expression accelerates the growth of breast cancer [28]. Thus, overexpression of the PER2 protein may be linked to apoptotic cell death in normal as well as several cancer cells.

\section{Acknowledgments}

This research was supported in part by a Grant-in-Aid for Scientific Research (B) from Japan Society for the Promotion of Sciences (JSPS; no.17658131; to M-A H). 


\section{References}

1. Reppert SM, Weaver DR (2001) Molecular analysis of mammalian circadian rhythms. Annu Rev Physiol 63:647-676.

2. Shearman LP, Sriram S, Weaver DR, Maywood ES, Chaves I, Zheng B, Kume K, Lee CC, van der Horst GT, Hastings MH, Reppert SM (2000) Interacting molecular loops in the mammalian circadian clock. Science 288:1013-1019.

3. Ueda HR, Hayashi S, Chen W, Sano M, Machida M, Shigeyoshi Y, Iino M, Hashimoto S (2005) System-level identification of transcriptional circuits underlying mammalian circadian clocks. Nat Genet 37:187-192.

4. Damiola F, Le Minh N, Preitner N, Kornmann B, Fleury-Olela F, Schibler U (2000) Restricted feeding uncouples circadian oscillators in peripheral tissues from the central pacemaker in the suprachiasmatic nucleus. Genes Dev 14:2950-2961.

5. Schibler U, Sassone-Corsi P (2002) A web of circadian pacemakers. Cell 111:919-922.

6. Yamamoto T, Nakahata Y, Soma H, Akashi M, Mamine T, Takumi T (2004) Transcriptional oscillation of canonical clock genes in mouse peripheral tissues. BMC Mol Biol 5:18.

7. Lemos DR, Downs JL, Urbanski HF (2006) Twenty-four-hour rhythmic gene 
expression in the rhesus macaque adrenal gland. Molecular Endocrinology 20:1164-1176.

8. Nakamura TJ, Moriya T, Inoue S, Shimazoe T, Watanabe S, Ebihara S, Shinohara K (2005) Estrogen differentially regulates expression of Per1 and Per2 genes between central and peripheral clocks and between reproductive and nonreproductive tissues in female rats. J Neurosci Res 82:622-630.

9. Dolatshad H, Campbell EA, O'Hara L, Maywood ES, Hastings MH, Johnson MH (2006) Developmental and reproductive performance in circadian mutant mice. Hum Reprod 21:68-79.

10. He PJ, Hirata M, Yamauchi N, Hattori M-A (2007a) Up-regulation of Per1 expression by estradiol and progesterone in the rat uterus. $\mathbf{J}$ Endocrinol 194:511-519.

11. Hirata M, He PJ, Shibuya N, Uchikawa M, Yamauchi N, Hashimoto S, Hattori M-A (2009) Progesterone, but not estradiol, synchronizes circadian oscillator in the uterus endometrial stromal cells. Mol Cell Biochem 324:31-38.

12. Morse D, Cermakian N, Brancorsini S, Parvinen M, Sassone-Corsi P (2003) No circadian rhythms in testis: Period1 expression is clock independent and developmentally regulated in the mouse. Mol Endocrinol 17:141-151.

13. Alvarez JD, Chen D, Storer E, Sehgal A (2003) Non-cyclic and developmental stage-specific expression of circadian clock proteins during murine 
spermatogenesis. Biol Reprod 69:81-91.

14. Alvarez JD, Sehgal A (2005) The thymus is similar to the testis in its pattern of circadian clock gene expression. J Biol Rhythms 20:111-121.

15. He PJ, Hirata M, Yamauchi N, Hashimoto S, Hattori M-A (2007b) The disruption of circadian clockwork in differentiating cells from rat reproductive tissues as identified by in vitro real-time monitoring system. J Endocrinol 193:413-420.

16. He PJ, Hirata M, Yamauchi N, Hashimoto S, Hattori M-A (2007c) Gonadotropic regulation of circadian clockwork in rat granulosa cells. Mol Cell Biochem 302:111-118.

17. Akashi M, Ichise T, Mamine T, Takumi T (2006) Molecular mechanism of cell-autonomous circadian gene expression of Period2, a crucial regulator of the mammalian circadian clock. Mol Biol Cell 17:555-565.

18. Balsalobre A, Brown SA, Marcacci L, Tronche F, Kellendonk C, Reichardt HM, Schutz G, Schibler U (2000a) Resetting of circadian time in peripheral tissues by glucocorticoid signaling. Science 289:2344-2347.

19. Balsalobre A, Marcacci L, Schibler U (2000b) Multiple signaling pathways elicit circadian gene expression in cultured Rat-1 fibroblasts. Curr Biol 10:1291-1294.

20. Tsuchiya Y, Minami I, Kadotani H, Nishida E (2005) Resetting of peripheral circadian clock by prostaglandin E2. EMBO Rep 6:256-261.

21. Hinoi E, Ueshima T, Hojo H, Iemata M, Takarada T, Yoneda Y (2006) 
Up-regulation of per mRNA expression by parathyroid hormone through a protein kinase A-CREB-dependent mechanism in chondrocytes. J Biol Chem 281:23632-23642.

22. Nakahata Y, Akashi M, Trcka D, Yasuda A, Takumi T (2006) The in vitro real-time oscillation monitoring system identifies potential entrainment factors for circadian clocks. BMC Mol Biol 7:5.

23. Shirai H, Oishi K, Ishida N (2006) Circadian expression of clock genes is maintained in the liver of Vitamin A-deficient mice. Neurosci Lett 398:69-72.

24. McKeehan WL, Adams PS, Fast D (1987) Different hormonal requirements for androgen-independent growth of normal and tumor epithelial cells from rat prostate. In Vitro Cell Dev Biol 23:147-152.

25. Lu J, Danielsen M (1998) Differential regulation of androgen and glucocorticoid receptors by retinoblastoma protein. J Biol Chem 273:31528-31533.

26. Catalona WJ (1994) Management of cancer of the prostate. New Engl J Med 331: 996-1004.

27. Xing RH, Rabbani SA (1999) Regulation of urokinase production by androgens in human prostate cancer cells: effect on tumor growth and metastases in vivo. Endocrinology 140:4056-4064.

28. Chen ST, Choo KB, Hou MF, Yeh KT, Kuo SJ, Chang JG (2005) Deregulated expression of the PER1, PER2 and PER3 genes in breast cancers. Carcinogenesis 
26: 1241-1246.

29. Hua H, Wang Y, Wan C, Liu Y, Zhu B, Yang C, Wang X, Wang Z, Cornelissen-Guillaume G, Halberg F (2006) Circadian gene mPer2 overexpression induces cancer cell apoptosis. Cancer Sci 97:589-596.

30. Ueda HR, Chen W, Adachi A, Wakamatsu H, Hayashi S, Takasugi T, Nagano M, Nakahama K, Suzuki Y, Sugano S, Iino M, Shigeyoshi Y, Hashimoto S (2002) A transcription factor response element for gene expression during circadian night. Nature 418:534-539.

31. Ravindranath N, Dym M (1999) Isolation of rat ventral prostate basal and luminal epithelial cells by the STAPUT technique. Prostate 41:173-180.

32. Sato F, Kurokawa M, Yamauchi N, Hattori M-A (2006) Gene silencing of myostatin in chicken embryonic myoblasts by small interfering RNA. Am J Physiol 291:C538-C545.

33. Han SJ, Tsai SY, Tsai MJ, O’Malley BW (2007) Distinct temporal and spatial activities of RU486 on progesterone receptor function in reproductive organs of ovariectomized mice. Endocrinology 148:2471-2486.

34. Heinlein CA, Chang C (2004) Androgen receptor in prostate cancer. Endocr Rev 25:276-308.

35. Pu Y, Huang L, Birch L, Prins GS (2007) Androgen regulation of prostate morphoregulatory gene expression: Fgf10-dependent and -independent pathways. 
Endocrinology 148:1697-1706.

36. Darlington TK, Wager-Smith K, Ceriani MJ, Staknis D, Gekakis N, Steeves TDL, Weitz CJ, Takahashi JS, Kay SA. 1998 Closing the circadian loop: CLOCK-induced transcription of its own inhibitors per and tim. Science 280:1599-1603.

37. Travnickova-Bendova Z, Cermakian N, Reppert SM, Sassone-Corsi P (2002) Bimodal regulation of mPeriod promoters by CREB-dependent signaling and CLOCK/BMAL1 activity. Proc Natl Acad Sci USA 99:7728-7733.

38. Pitkanen-Arsiola T, Tillman JE, Gu G, Yuan J, Roberts RL, Wantroba M, Coetzee GA, Cookson MS, Kasper S (2006) Androgen and anti-androgen treatment modulates androgen receptor activity and DJ-1 stability. Prostate 66:1177-1193.

39. Yoon HG, Wong $\mathbf{J}$ (2006) The corepressors silencing mediator of retinoid and thyroid hormone receptor and nuclear receptor corepressor are involved in agonist- and antagonist-regulated transcription by androgen receptor. Mol Endocrinol 20:1048-1060.

40. Montalvo L, Carmena MJ, Bolanos O, Rodriguez-Henche N, Sanchez-Chapado M, Prieto JC (2004) Effects of the antiandrogen flutamide on the expression of protein kinase $\mathrm{C}$ isoenzymes in $\mathrm{LNCaP}$ and PC3 human prostate cancer cells. Biosci Rep 24:11-21.

41. Vindrieux D, Reveiller M, Florin A, Blanchard C, Ruffion A, Devonec M, 
Benahmed M, Grataroli R (2006) TNF- $\alpha$-related apoptosis-inducing ligand decoy receptor DcR2 is targeted by androgen action in the rat ventral prostate. $\mathrm{J}$ Cell Physiol 206:709-717.

42. Fu L, Pelicano H, Liu J, Huang P, Lee C (2002) The circadian gene Period2 plays an important role in tumor suppression and DNA damage response in vivo. Cell 111: 41-50.

43. Stevens RG, Rea MS (2001) Light in the built environment: potential role of circadian disruption in endocrine disruption and breast cancer. Cancer Causes Control 12: 279-287.

44. Zhu Y, Brown HN, Zhang Y, Stevens RG, Zheng T (2005) Period3 structural variation: a circadian biomarker associated with breast cancer in young women. Cancer Epidemiology Biomarkers Prev 14:268-270.

45. Gery S, Virk RK, Chumakov K, Yu A, Koeffler HP (2007) The clock gene Per2 links the circadian system to the estrogen receptor. Oncogene 26:7916-7920. 


\section{Figure legends}

Fig. 1. Immunofluorescence analysis for the PER2 and AR proteins in the rat prostate.

a: Prostate sections stained with Hoechst. The square region shown in a is magnified from a serial section subjected to immunofluorescence studies as shown in $\mathbf{b}$ and $\mathbf{c}$. $\mathbf{b}$ : Immunostaining with anti-PER2 antibody (red) on a section of prostate. c: Immunostaining with anti-AR antibody (green) on a section of prostate. d: PER2 and AR proteins merged image. Bars: $250 \mu \mathrm{m}(\mathbf{a}), 50 \mu \mathrm{m}(\mathbf{b}-\mathbf{d})$

Fig. 2. ARE-luciferase reporter assay in isolated PMCs. A: ARE-constructed pGL3-promoter luciferase reporter plasmid was transfected to PMCs. At time $0 \mathrm{~h}$, cells were given in replaced fresh medium supplemented with $0.1 \mathrm{mM}$ luciferin and $\mathrm{T}(1,10$ $\mu \mathrm{M}$ ) or vehicle (as a control). B: Immunofluorescence analysis for the AR proteins in the cultured PMCs. a, Bright view. b. Immunostaining with anti-AR antibody (green). Scale bars: $150 \mu \mathrm{m}$.

Fig. 3. Generation of circadian Per2-dLuc oscillations in PMCs. At time 0 h, cells were given in replaced fresh medium supplemented with $0.1 \mathrm{mM}$ luciferin, and $0.1 \mu \mathrm{M}$ DXM, $1 \mu \mathrm{M}$ forskolin or vehicle (as a control). 
Fig. 4. Profiles of circadian Per2-dLuc oscillations in PMCs treated with androgens or FL. At time $0 \mathrm{~h}$, cells were given in replaced fresh medium supplemented with $0.1 \mathrm{mM}$ luciferin, and T, DHT, FL (each $1 \mu \mathrm{M}$ ) or vehicle (as a control). A: Real-time bioluminescent activity was monitored in PMCs treated with vehicle, T, DHT or FL. P1-3: first to third peaks, T1-2: first to second troughs. B: The peaks and troughs were normalized to the values of the control cells treated with vehicle and data are means \pm SE of three determinations. Values with different letters are significantly different $(P<0.05)$.

Fig. 5. Dose-dependent increases in the amplitude of circadian Per2-dLuc oscillations in PMCs treated with FL. At time $0 \mathrm{~h}$, cells were given in replaced fresh medium supplemented with $0.1 \mathrm{mM}$ luciferin, and FL $(0.1,1,10 \mu \mathrm{M})$ or vehicle (as a control). A: Real-time bioluminescent activity was monitored in PMCs treated with vehicle or FL. B: Each first peak was normalized to the values of the control cells treated with vehicle and data are means \pm SE of three determinations. Values with different letters are significantly different $(P<0.05)$.

Fig. 6. Inhibitory effects of $\mathrm{T}$ on the amplitude of circadian Per2-dLuc oscillations in PMCs treated with FL. Cultured PMCs were treated with increasing concentrations of $\mathrm{T}(0.1,1,10 \mu \mathrm{M})$ or vehicle (as a control). At time $0 \mathrm{~h}$, cells were given in replaced 
fresh medium supplemented with $0.1 \mathrm{mM}$ luciferin, $\mathrm{T}$ (same concentrations), and $1 \mu \mathrm{M}$ FL or vehicle (as a control). A: Real-time bioluminescent activity was monitored in PMCs treated with FL and T. B: Each first peak was normalized to the values of the control cells treated with vehicle and data are means \pm SE of three determinations. Values with different letters are significantly different $(P<0.05)$.

Fig. 7. Immunofluorescence analysis of PER2 protein in PMCs treated with or without FL during circadian Per2-dLuc oscillations. (Panels a-g) Images were taken from PMCs treated with vehicle at the first peak (P1) (34 h) (a-c, g) and first trough (T1) (48 h) (d-f) of circadian oscillations. (Panels h-n) Images were taken from PMCs treated with FL at the first peak (P1) (34 h) (h-j, n) and first trough (T1) (48 h) (k-m) of circadian oscillations. (Panels g and n) Magnified PER2 protein and Hoechst staining merged images in the square regions shown in panels $\mathrm{c}$ and j. In FL-treated cells, especially apoptotic cells were detected (arrowheads). red: PER2 protein, blue: Hoechst. Scale bars: $150 \mu \mathrm{m}$.

Fig. 8. Determination of apoptotic cell death in PMCs cultured with or without FL. PMCs were treated with $1 \mu \mathrm{M}$ FL or vehicle (as a control) and taken at the first peak (P1) (34 h) and first trough (T1) (48 h) of circadian oscillations. PMCs were subjected to PI staining (apoptotic cells) and Hoechst staining (total cells). Data are means $\pm \mathrm{SE}$ 
of three determinations. ${ }^{*}, P<0.05$ versus control. 
Table 1. Changes of PER2 staining intensity in PMCs treated with or without FL during circadian Per2-dLuc oscillations as revealed by immunofluorescence.

The experiments were independently repeated at least 3 times, and data were expressed as means \pm SE. Different letters are significant $(P<0.05)$.

\begin{tabular}{lcc}
\hline Treatment & Position & PER2 staining intensity \\
& & (Arbitrary units) \\
\hline Control & P1 & $35.62 \pm 2.11 \mathrm{a}$ \\
& $\mathrm{T} 1$ & $21.31 \pm 0.47 \mathrm{~b}$ \\
Flutamide & $\mathrm{P} 1$ & $89.83 \pm 9.67 \mathrm{c}$ \\
& $\mathrm{T} 1$ & $23.89 \pm 0.38 \mathrm{~d}$ \\
\hline
\end{tabular}


FIG. 1
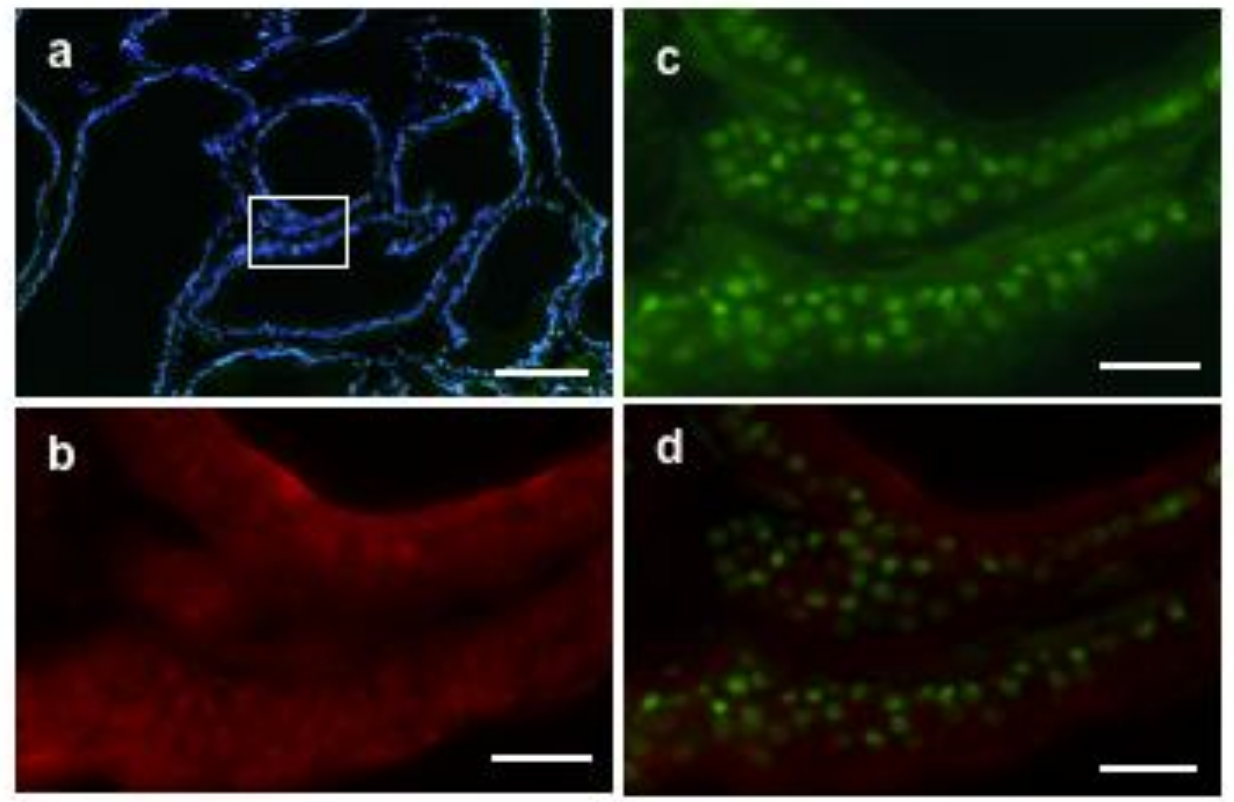

FIG. 2

A

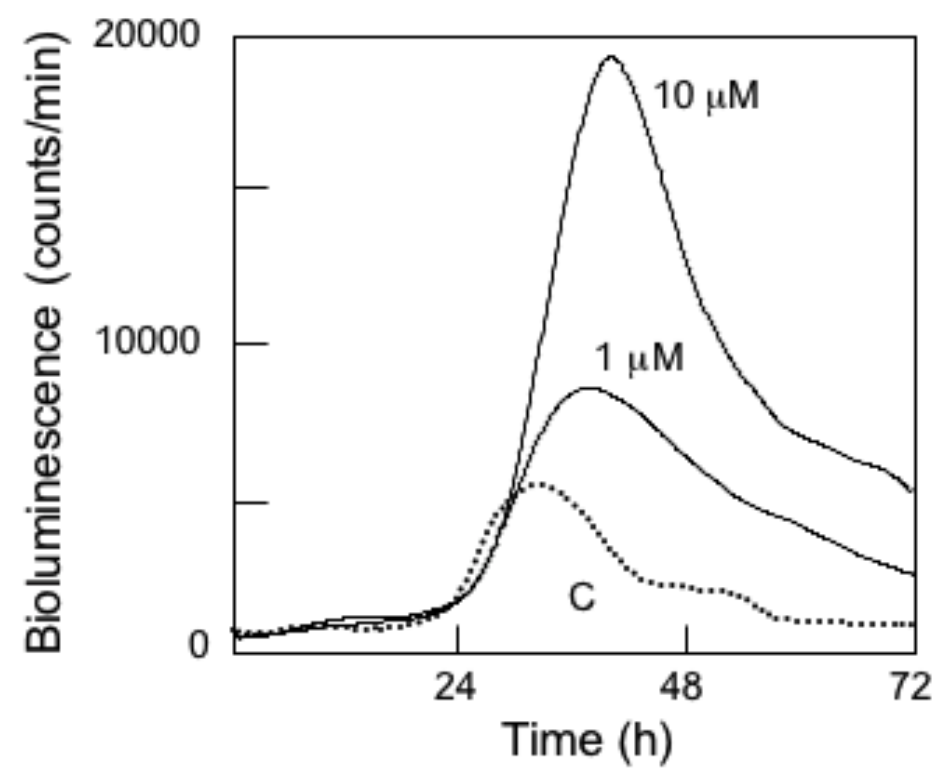

B

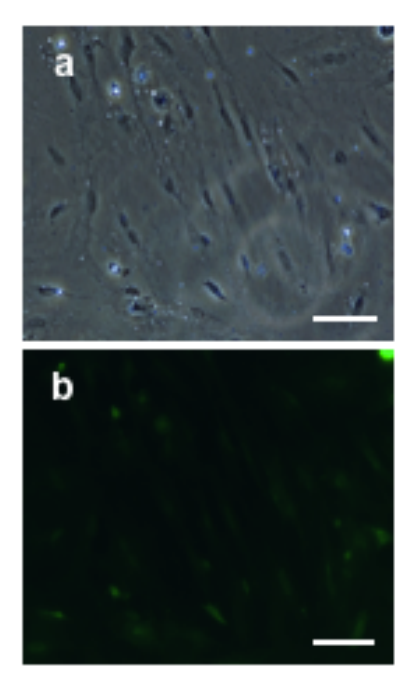


FIG. 3

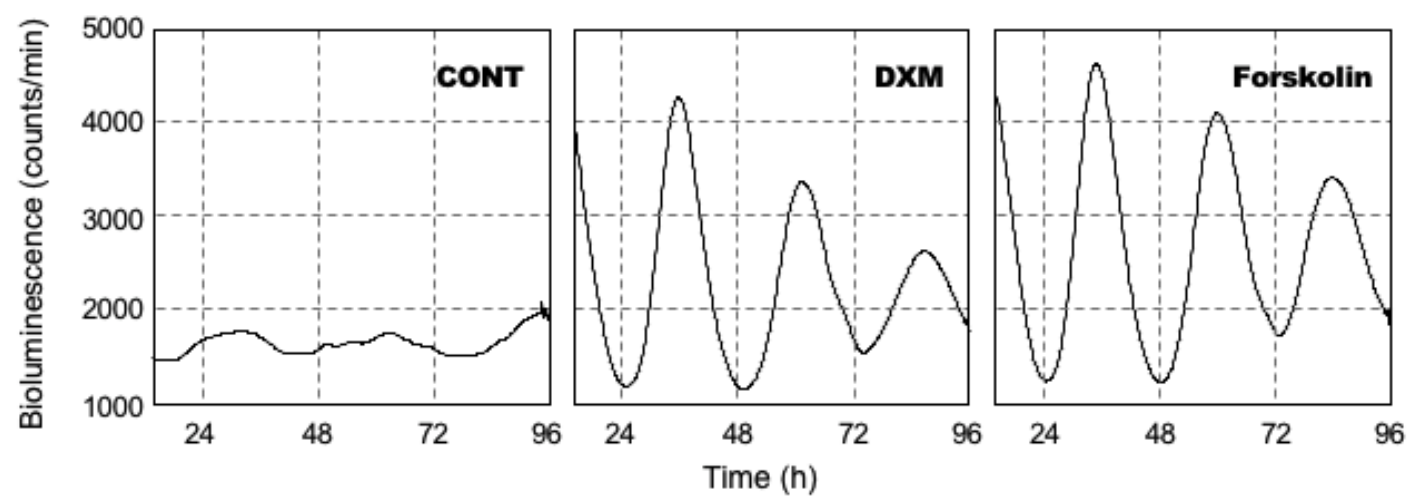

FIG. 4
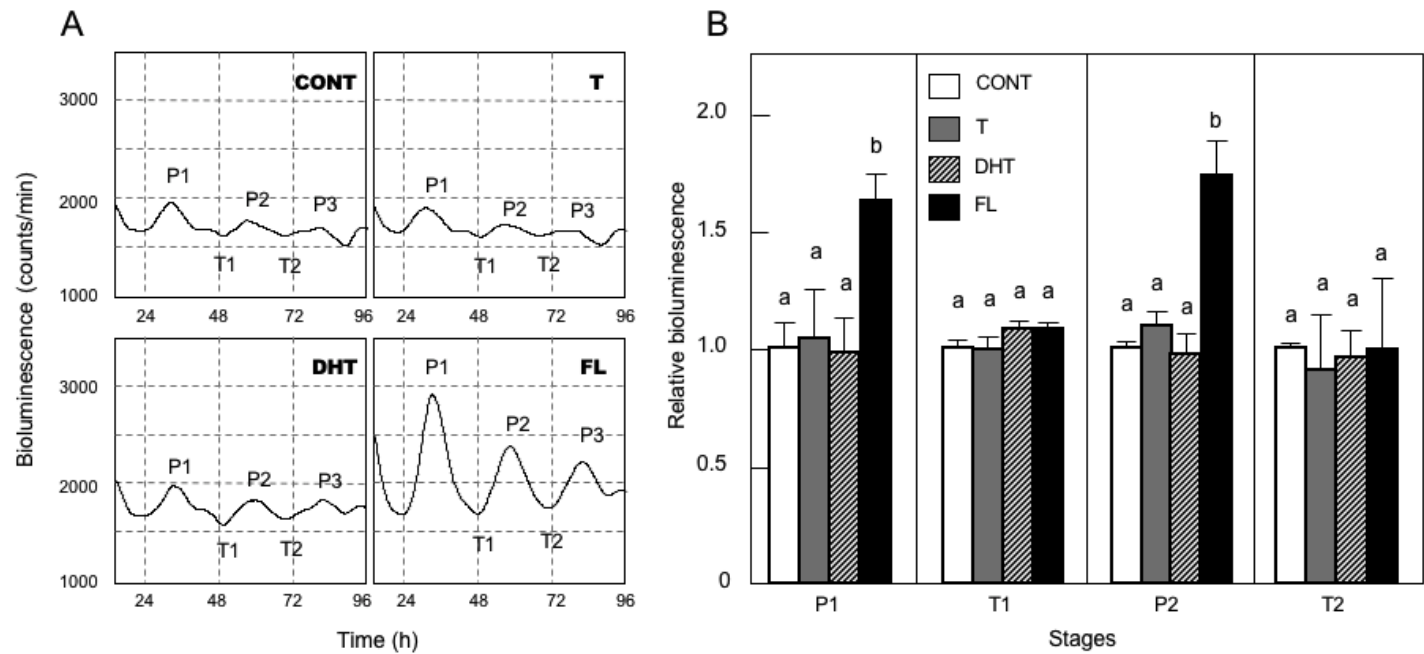
FIG. 5
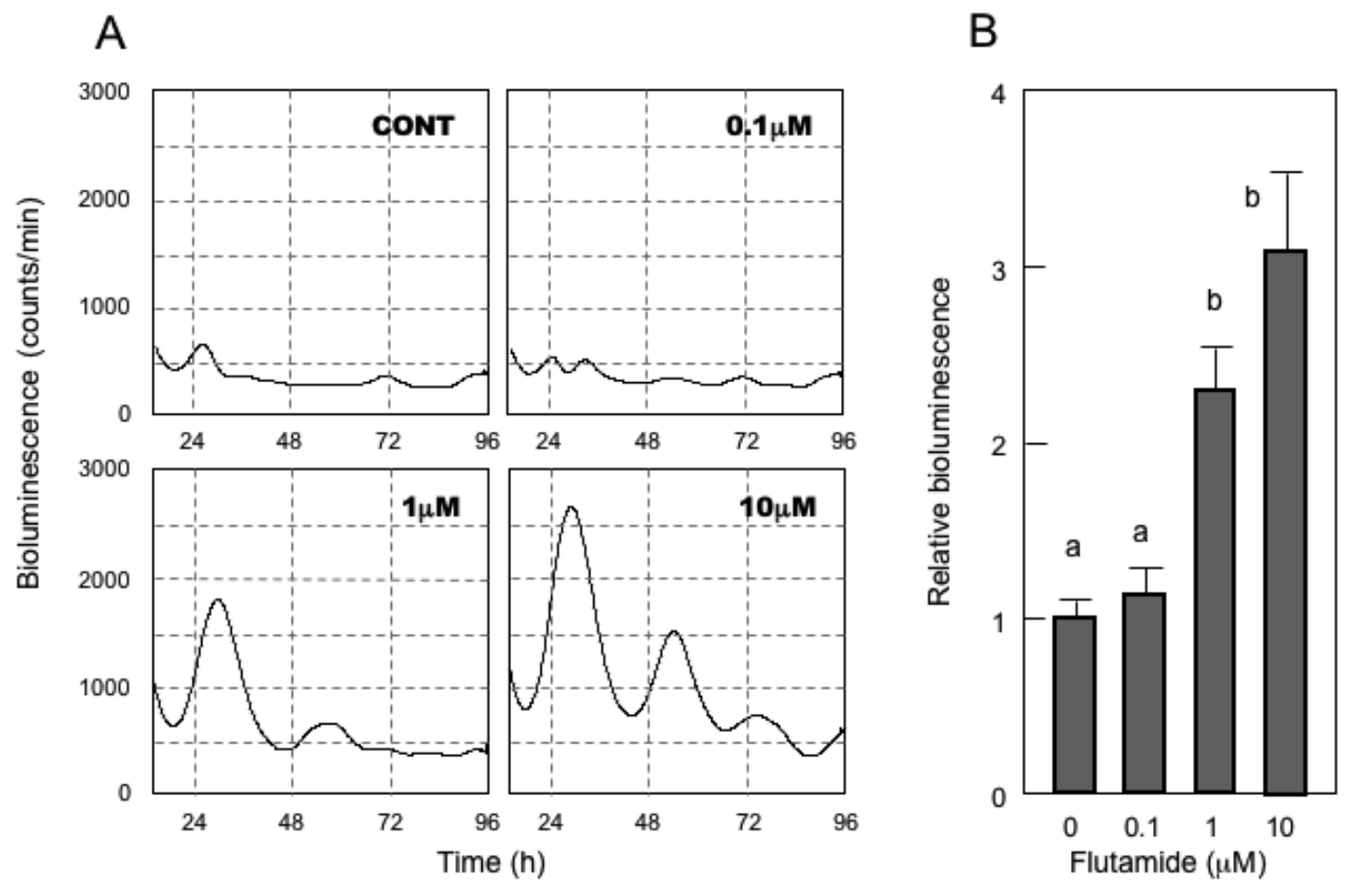

FIG. 6

A

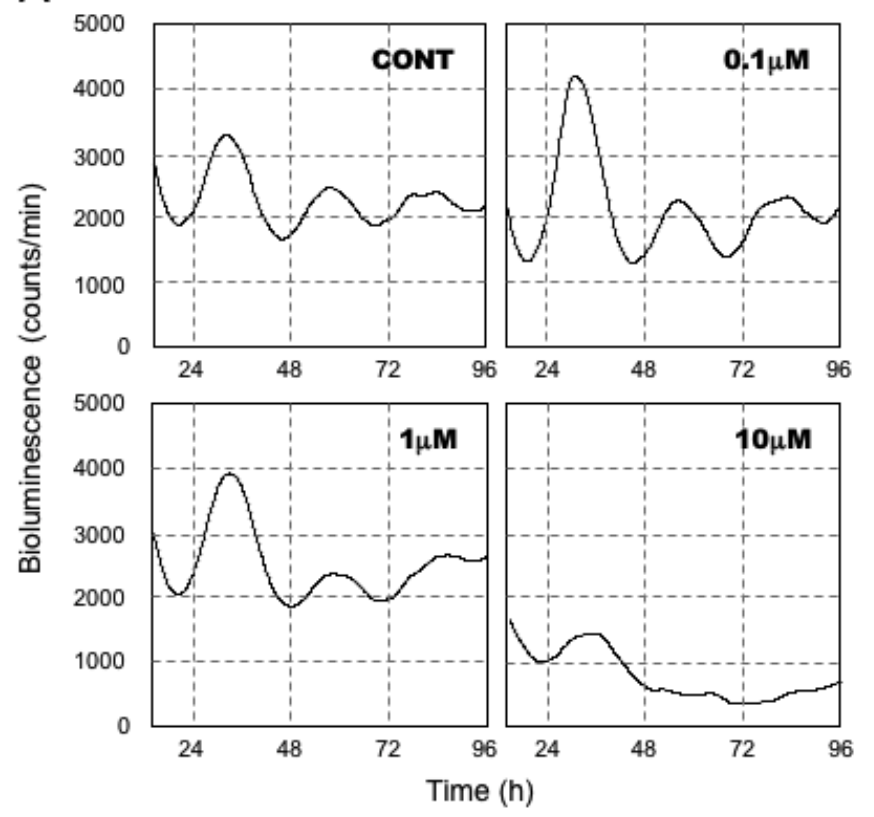

B

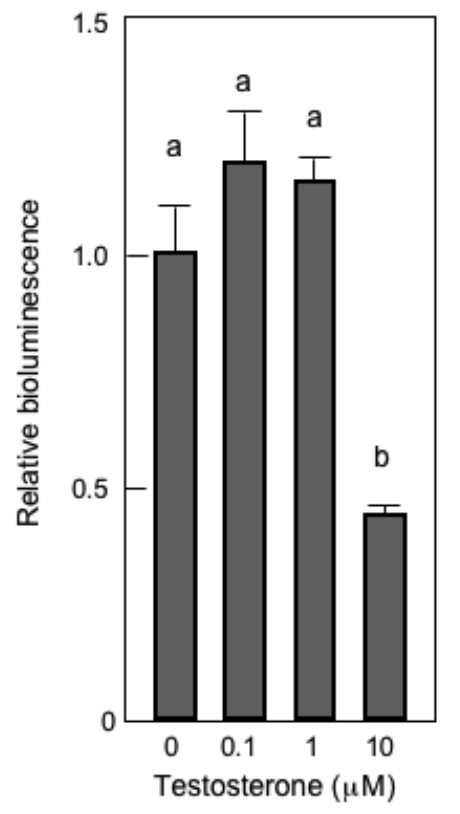


FIG. 7
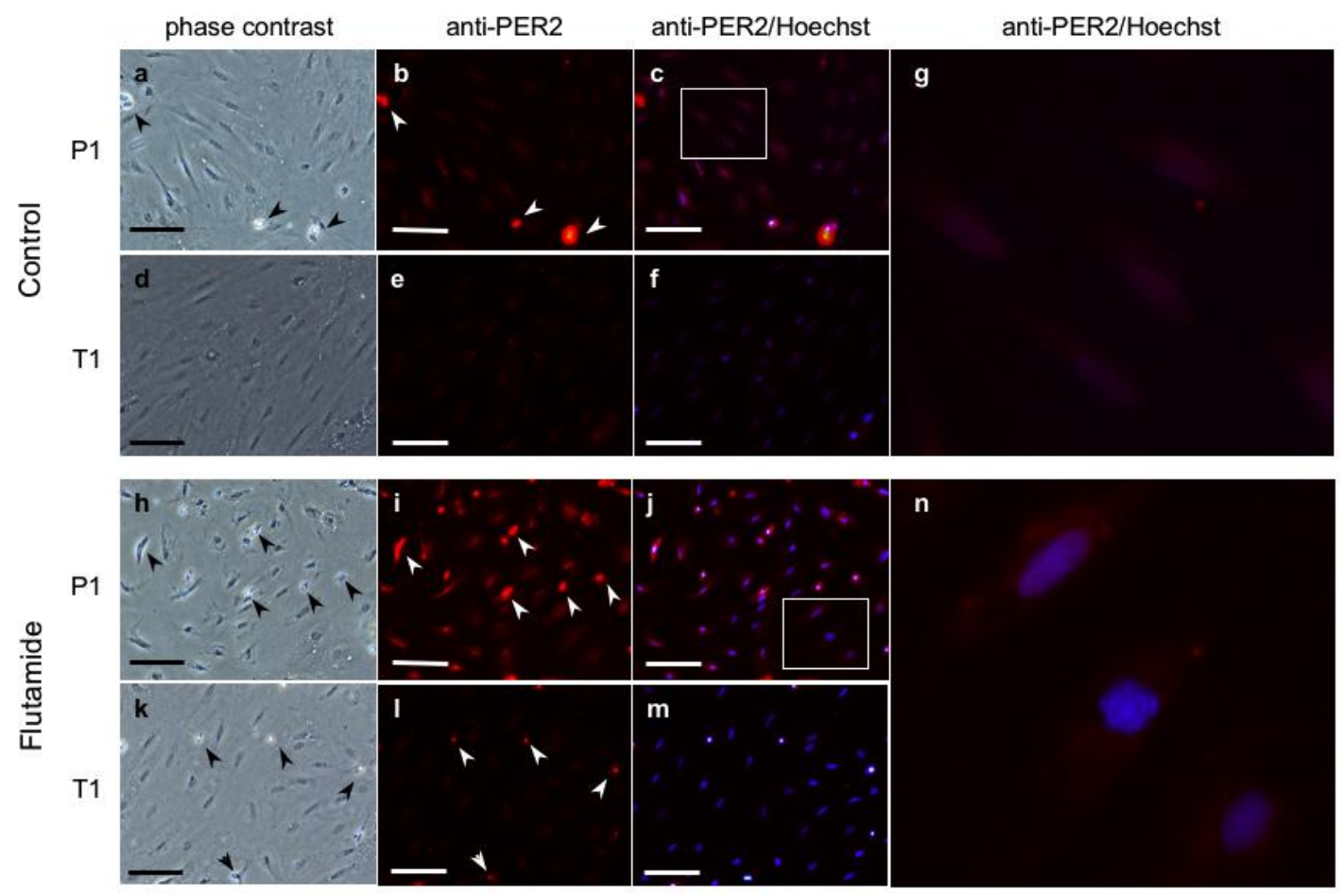

FIG. 8

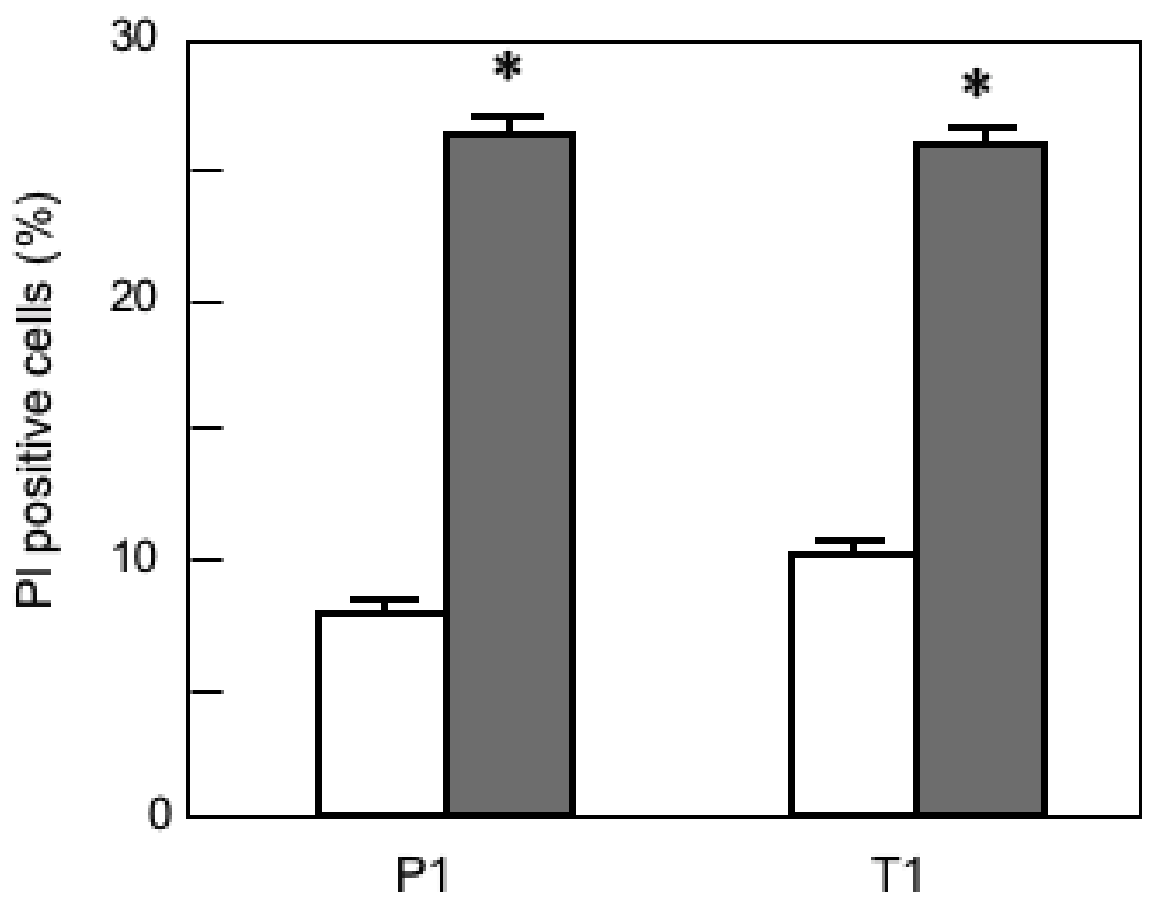

